\title{
Strategies and Steps to Assigning an Accurate DSM-5 Diagnosis
}

\author{
Diane A Suffridge* \\ Psychologist, Dominican University of California, USA
}

Submission: April 08, 2017; Published: April 17, 2017

*Corresponding author: Diane A. Suffridge, Ph.D., Assistant Professor, Dominican University of California, Consultant, Trainer and author in behavioral health, Adult psychotherapy, Licensed Psychologist, USA, Tel: 415-578-0960; Email: www.dianesuffridgephd.com

Abstract

This article outlines several strategies for assigning an accurate DSM-5 diagnosis after the first session. It then! describes three steps to use in developing a comprehensive diagnosis when a complete assessment has taken place.

\section{Introduction}

Behavioral health agencies often require clinicians to assign a diagnosis after the first session with the patient. This requirement is usually related to third party billing and the need to document the medical necessity of the services being provided. While this requirement insures that patients have access to the services they need, it can be frustrating as a clinician to assign a diagnosis without the chance to develop a comprehensive understanding of the patient's symptoms. I suggest some strategies regarding the notation of the diagnosis itself and outline a three-step process for arriving at a diagnosis after the first session or after a more thorough assessment. My comments are based on using the Diagnostic and Statistical Manual of Mental Disorders, Fifth Edition (DSM-5) as the basis for diagnosis [1].

One strategy regarding the assignment of a diagnosis after one session is to use the term "Provisional." This is allowed by some third party insurers, and it is a way to acknowledge that the diagnosis is tentative. Situations in which a "provisional" diagnosis are appropriate are 1) when a patient meets most of the criteria but the clinician hasn't confirmed the full set of criteria required for the diagnosis or 2) when the patient reports a diagnosis given by another health care provider that the treatment clinician hasn't verified independently. The use of "Other Specified" and "Unspecified" diagnoses are also possible when the clinician has determined which category the client's symptoms fit but doesn't have complete information about the criteria for a specific diagnosis within that category.
A second strategy for assigning a diagnosis after one session is to view diagnosis as an ongoing process that is open to modification, rather than a decision that is made once for the duration of the patient's treatment. The diagnosis assigned after the first session may not be the diagnosis that accurately reflects the patient's history and symptoms that emerge after the clinician has completed an assessment. At times the patient's initial presentation differs from the impression gathered after four to six sessions. Reviewing the diagnosis every six months or when updating the treatment plan is a way to insure the accuracy. The diagnosis can be updated if appropriate, to reflect changes in the patient's symptoms or new historical information.

I have developed a three-step process to help new clinicians develop a diagnosis, and the worksheet reflecting this process is available for download in an online workbook [2]. I find that new clinicians often have difficulty prioritizing the different pieces of information they have about patients, and this leads to confusion in identifying the most accurate diagnosis.

I. The first step to developing a diagnosis is to list the patient's current symptoms and past symptoms reported as part of the history. This insures consideration of all of the data relevant to the diagnosis rather than prematurely focusing on one aspect of the presentation that may lead to an inaccurate diagnosis or may neglect a secondary diagnosis that is clinically important.

II. The second step is to make note of the categories in the DSM-5 that fit the patient's symptoms, being as comprehensive 
as possible. In the worksheet, I suggest noting the categories in which symptoms are present (or are part of the history) and then noting whether these symptoms are relevant to the current treatment, i.e., part of the reason for the client seeking treatment. This notation will serve as a reminder to address the relevant symptoms in the treatment plan. Remember to include the "Other Conditions" category if the patient has psychosocial stressors, relationship difficulties, or a history of trauma.

III. The third step is to look at the specific diagnoses within the categories noted to see whether the patient's symptoms meet the criteria for one or more diagnoses. It is also important to review the codes in the "Other Conditions" category to determine which situational factors are important to include in the diagnosis. Often, the patient's clinical presentation may be best described by one or more diagnoses and one or more $\mathrm{Z}$ codes. If this is the case, it is best to choose the diagnosis that best represents the reason for treatment as the primary diagnosis which will be reported for billing purposes. The other diagnoses can be included in the assessment report to provide a comprehensive view of the patient's symptoms, history, and current psychosocial stressors.

\section{References}

1. American Psychiatric Association (2013) Diagnostic and statistical manual of mental disorders ( $5^{\text {th }}$ edn). Arlington, Texas, USA.

2. Suffridge DA (2016) Entering the behavioral health field: A guide for new clinicians. Routledge, New York, USA.

\section{Your next submission with JuniperPublishers will reach you the below assets}

- Quality Editorial service

- Swift Peer Review

- Reprints availability

- E-prints Service

- Manuscript Podcast for convenient understanding

- Global attainment for your research

- Manuscript accessibility in different formats

( Pdf, E-pub, Full Text, Audio)

- Unceasing customer service

Track the below URL for one-step submission https://juniperpublishers.com/online-submission.php 